\title{
NS-398 enhances the efficacy of bortezomib against RPMI8226 human multiple myeloma cells
}

\author{
WENZHONG QUE ${ }^{1}$, SAIYUAN LI $^{2}$ and JUNMIN CHEN ${ }^{3}$ \\ ${ }^{1}$ Department of Hematology and Rheumatology, The Third Affiliated Hospital of Fujian Medical University, Fuzhou 350003; \\ ${ }^{2}$ Department of Pediatrics, The Children's Hospital of Fuzhou, Fuzhou 350005; \\ ${ }^{3}$ Department of Hematology and Rheumatology, The First Affiliated Hospital \\ of Fujian Medical University, Fuzhou 350005, P.R. China
}

Received October 26, 2012; Accepted February 15, 2013

DOI: $10.3892 / \mathrm{mmr} .2013 .1394$

\begin{abstract}
Bortezomib is commonly used in treating multiple myeloma (MM). However, a number of patients develop resistance to bortezomib over time. Cox- 2 is overexpressed in $\mathrm{MM}$ cells and contributes to apoptosis resistance and MM development. In the present study, RPMI8226 MM cells were treated with the Cox-2 inhibitor NS-398 to investigate whether it enhanced the effect of bortezomib on MM. The results showed that NS-398 and bortezomib acted synergistically to inhibit growth, arrest the cell cycle at the $G_{1}$ phase and to induce the apoptosis of MM cells. NS-398 inhibited the NF- $\mathrm{NB}$ p65 protein levels and the expression of various $\mathrm{NF}-\kappa \mathrm{B}$ target genes, including cyclin D1, c-Myc, survivin and Bcl-2. In conclusion, NS-398 enhanced the efficacy of bortezomib against MM cells in vitro and this was associated with the inhibition of NF- $\kappa \mathrm{B}$ signaling. These findings suggest that the combined use of NS-398 and bortezomib may constitute a promising novel treatment protocol for MM patients.
\end{abstract}

\section{Introduction}

Multiple myeloma (MM) is a B-cell malignancy characterized by the clonal proliferation of neoplastic plasma cells in the bone marrow (BM). MM is an incurable disease (1). Bortezomib (Velcade ${ }^{\circledR}$ ) was developed as an anticancer drug that acts by inhibiting the $26 \mathrm{~S}$ proteasome complex and exhibiting a strong cytotoxic effect against MM cells (2-4). Nevertheless, numerous MM patients who initially respond well, inevitably develop resistance to this drug.

Previous studies have demonstrated that MM cells become refractory to bortezomib possibly due to their increased constitutive NF- $\mathrm{NB}$ activity, which is further increased when

Correspondence to: Professor Junmin Chen, Department of Hematology and Rheumatology, The First Affiliated Hospital of Fujian Medical University, 20 Chazhong Road, Fuzhou 353005, P.R. China

E-mail: drjunminchen@hotmail.com

Key words: NS-398, bortezomib, multiple myeloma, NF-кB cultured with MM patient-derived bone marrow stromal cells (BMSCs). In addition, increased $\mathrm{NF}-\kappa \mathrm{B}$ activity in the MM RPMI8226 cell line has been correlated with a decreased bortezomib sensitivity in vitro $(5,6)$.

Prostaglandin E2 (PGE2) has been shown to upregulate the expression of Cox-2 or to contribute to its direct stabilization (7-9). Upon binding with its cell surface receptors, PGE2 has been shown to exert anti-apoptotic and proliferative effects which may promote carcinogenesis and to a certain extent, abrogate the anti-tumor effects of proteasome inhibition (10). In addition, NS-398 (a Cox-2 highly selective inhibitor) has been demonstrated to inhibit cell growth and induce apoptosis by inhibiting the NF- $\mathrm{BB}$ pathway (11). Thus, Cox-2 inhibition is a potentially effective way to enhance the efficacy of bortezomib.

In the present study, the RPMI8226 cell line was used as a model to determine the in vitro effects of NS-398 and bortezomib on MM RPMI8226 cells, with the aim of investigating the possibile treatment of MM by combined use of NS-398 and bortezomib.

\section{Materials and methods}

Cell culture and reagents. RPMI8226 cells (American Type Culture Collection, Manassas, VA, USA) were cultured in RPMI-1640 medium supplemented with $10 \%$ fetal calf serum (Gibco-BRL, Grand Island, NY, USA) and maintained in a 5\% $\mathrm{CO}_{2}$ incubator at $37^{\circ} \mathrm{C}$. The highly selective Cox-2 inhibitor, NS-398 (Sigma, St. Louis, MO, USA), and the bortezomib (LC Laboratories, Woburn, MA, USA) were dissolved in dimethyl sulfoxide (DMSO; Sigma) and stored at $-20^{\circ} \mathrm{C}$. The two drugs were diluted in culture medium $\left(10^{-4}-10^{-2} \mathrm{~mol} / \mathrm{l}\right)$ with $<0.1 \%$ DMSO immediately prior to use. The study was approved by the Ethics Committee of Fujian Medical University, Fuzhou, China.

Cell growth assay. RPMI8226 cells were seeded in triplicate at a density of $5 \times 10^{3}$ cells/well in 96-well plates and $180 \mu \mathrm{l}$ RPMI-1640 medium containing various concentrations of bortezomib and/or NS-398. The cells were cultured for 24, 48 or $72 \mathrm{~h}$. Subsequently, $20 \mu \mathrm{l}$ of MTT substrate $(5 \mathrm{mg} / \mathrm{ml})$ was added to each well, and the plates were returned to the standard cell incubator for an additional $4 \mathrm{~h}$. The supernatants were then carefully removed and $200 \mu \mathrm{l}$ DMSO was 
added to each well. After the insoluble crystals were completely dissolved, colorimetric analysis was performed at a wavelength of $570 \mathrm{~nm}$. The inhibition rate was calculated as follows: $100 \%$ - (individual OD value / control OD value)\%. Each independent experiment was performed three times. The formula presented by Jin (12) was calculated as: $\mathrm{Q}=\mathrm{Ea}+\mathrm{b} /(\mathrm{Ea}+\mathrm{Eb}-\mathrm{Ea} \times \mathrm{Eb}) . \mathrm{Q}$ was the combination index; $\mathrm{Ea}+\mathrm{b}$ represented the inhibition rate of the combined drug $(\mathrm{A}+\mathrm{B})$; and $\mathrm{Ea}$ and $\mathrm{Eb}$ represented the inhibition rates of $\mathrm{A}$ and $\mathrm{B}$, respectively. When the $\mathrm{Q}$ value ranged betweeb 0.85 and 1.15 , the combined drug effect was a simple 'arithmetic' sum. A Q value of $>1.15$ indicated a synergic effect, while a $Q$ value of $<0.85$ indicated an antagonistic effect.

Flow cytometric analysis of apoptosis and the cell cycle. RPMI8226 cells were seeded in quadruplicate at a density of $5 \times 10^{6}$ cells/well in 6-well plates and $3 \mathrm{ml}$ of RPMI-1640 medium containing various concentrations of bortezomib and/or NS-398. Subsequent to culturing for $48 \mathrm{~h}$, the cells were collected, washed twice with ice-cold phosphate-buffered saline (PBS) and fixed with $70 \%$ ethanol at $4^{\circ} \mathrm{C}$ overnight. Following washing with PBS, the cells were incubated in $0.5 \mathrm{ml}$ PBS containing $50 \mu \mathrm{g} / \mathrm{ml}$ RNase A for $\sim 30 \mathrm{~min}$ at $37^{\circ} \mathrm{C}$. Propidium iodide (PI) was then added (Keygen, Nanjing, China) to a final concentration of $50 \mu \mathrm{g} / \mathrm{ml}$ and incubated for $30 \mathrm{~min}$ on ice in the dark. The resultant cell suspension was then subjected to flow cytometry (Becton-Dickinson, Franklin Lakes, NJ, USA). The percentage of the apoptotic cells (subG1) and the cells in the G0/G1, S and G2/M phases was calculated using CellQuest software (Becton-Dickinson).

Cox activity assay. The activity of Cox-2 was measured using the COX Activity Assay kit (Cayman Chemical, Ann Arbor, MI, USA) according to the manufacturer's instructions. The cells were collected at $4^{\circ} \mathrm{C}$. Cell pellets were then homogenized in the cold buffer provided with the kit and centrifuged at $10,000 \mathrm{x} \mathrm{g}$ at $4^{\circ} \mathrm{C}$ for $10 \mathrm{~min}$. Then, $10 \mu \mathrm{l}$ of supernatant was added into each well of a 96-well plate and mixed with $150 \mu$ l assay buffer and $10 \mu \mathrm{l}$ heme. The supernatant samples, which were boiled for 5 min, were matched with each well as the controls. The 96-well plate was carefully agitated for $1 \mathrm{~min}$ and incubated at $37^{\circ} \mathrm{C}$ for $5 \mathrm{~min}$, then $20 \mu \mathrm{l}$ colorimetric substrate and arachidonic acid were added to each well. The plate was carefully agitated again and incubated at $37^{\circ} \mathrm{C}$ for $5 \mathrm{~min}$. Colorimetric analysis was performed at a wavelength of $570 \mathrm{~nm}$.

Western blot analysis. The cells were collected and lysed at $4{ }^{\circ} \mathrm{C}$ for $30 \mathrm{~min}$. Once the protein concentration had been determined using the Lowry method, equal amounts of protein were separated on $6-15 \%$ SDS-PAGE gels. The protein was transferred to polyvinylidene fluoride (PVDF) membranes, which were blocked with 5\% skimmed milk in TBST (tris-buffered saline solution containing $0.1 \%$ Tween-20) at $4^{\circ} \mathrm{C}$ overnight, and then incubated with antibodies for NF- $\mathrm{NB}, \mathrm{Cox}-2$, c-Myc, Bcl-2, survivin, cyclin D1 and GAPDH (Santa Cruz Biotechnology Inc., Santa Cruz, CA, USA) for $2 \mathrm{~h}$ at room temperature. Following washing with TBST, the membranes were incubated with horseradish peroxidase (HRP)-labeled secondary antibodies for $1 \mathrm{~h}$ at $37^{\circ} \mathrm{C}$ and then developed using the enhanced chemiluminescence (ECL) reagent kit (Beyotime, Jiangsu, China).
Statistical analysis. Data were expressed as the mean \pm standard deviation (SD) and the Student's t-test was used to determine the significance of the differences between the drugs and controls. $\mathrm{P}<0.05$ was considered to indicate a statistically significant difference.

\section{Results}

NS-398 and bortezomib act synergistically to inhibit the growth of RPMI8226 MM cells. An MTT assay was performed to evaluate the effects of NS-398 and bortezomib on the growth of the RPMI8226 cells. The results showed that $20 \mu \mathrm{M}$ NS-398 inhibited RPMI8226 cell growth with inhibition rates of 33.7, 41.9 and $66.1 \%$ following 24-, 48- and 72-h treatments, respectively. Moreover, exposure of the cells to a $2.5-160 \mu \mathrm{M}$ range of NS-398 for $48 \mathrm{~h}$ inhibited cell proliferation in a dose-dependent manner. The half maximal inhibitory concentration $\left(\mathrm{IC}_{50}\right)$ of NS-398 for $48 \mathrm{~h}$ was $44.1 \mu \mathrm{M}$ (Fig. 1A and B). Similarly, bortezomib inhibited RPMI8226 cell growth in a dose- and time-dependent manner. The $\mathrm{IC}_{50}$ of bortezomib for $48 \mathrm{~h}$ was $48.4 \mathrm{nM}$ (Fig. 1C and D). The combination index was calculated to determine whether there was synergy between NS-398 and bortezomib in the inhibition of MM cell growth. The results showed that following treatment of the cells with 2, 10, 50 and $250 \mathrm{nM}$ of bortezomib for $48 \mathrm{~h}$, the inhibitory rate of cell growth was $6.7,15.1,52.3$ and $91.2 \%$, respectively, while the inhibitory rate was $41.9 \%$ following treatment with $20 \mu \mathrm{M}$ NS-398. When $20 \mu \mathrm{M}$ NS-398 was combined with these concentrations of bortezomib, the inhibitory rate of cell growth was increased to 58.7, 76.9, 91.4 and $97.7 \%$, respectively $(\mathrm{P}<0.05)$, and the combined index was $1.28,1.52,1.26$ and 1.03, respectively (Fig. 1E). These results demonstrate that NS-398 and bortezomib act synergistically by inhibiting the growth of RPMI8226 MM cells. To better characterize the synergistic action between the two drugs, $50 \mathrm{nM}$ bortezomib and $20 \mu \mathrm{M}$ NS-398 were used in the subsequent experiments.

NS-398 promotes bortezomib-induced apoptosis and the cell cycle arrest of RPMI8226 MM cells. To analyze the synergistic action between NS-398 and bortezomib, apoptosis and the cell cycle of the RPMI8226 cells treated by these two drugs were examined. As shown in Fig. 2, following treatment of the RPMI8226 cells with $50 \mathrm{nM}$ bortezomib and $20 \mu \mathrm{M}$ NS-398, the rate of apoptosis was 22.4 and $19.6 \%$, respectively. The combination of the bortezomib and NS-398 treatments led to an apoptotic rate of $61.2 \%$, which was higher than the sum of the rate when the cells were treated with each drug alone. In addition, Table I shows the percentage of cells arrested in the $\mathrm{G} 0 / \mathrm{G} 1$ phase as $47.5 \pm 3.8$ and $41.6 \pm 3.3 \%$ following the bortezomib and NS-398 treatments, respectively. These results were higher than that of the control $(25.4 \pm 3.3 \%$; $\mathrm{P}<0.05)$. The combined drug treatment led to a higher percentage of cells being arrested in the G0/G1 phase. Taken together, these data suggest that NS-398 promotes bortezomib-induced apoptosis and the cell cycle arrest of MM cells.

NS-398 inhibits bortezomib-induced Cox-2 activity in RPMI8226 MM cells. As shown in Fig. 3, NS-398 completely suppressed the increased Cox-2 activity induced by bortezomib in the RPMI8226 cells (Fig. 3). To investigate whether 
A

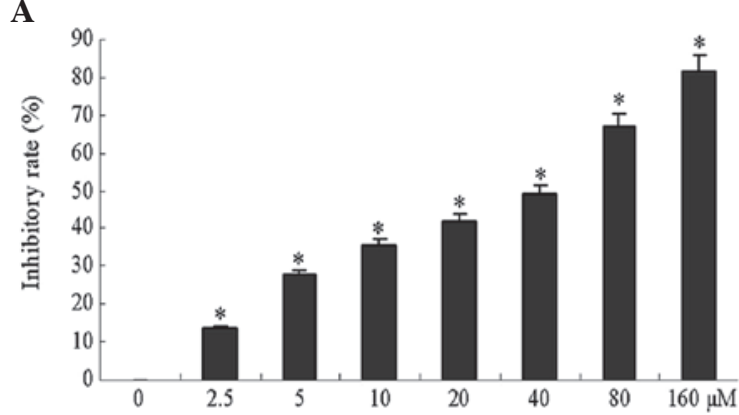

$\mathbf{B}$
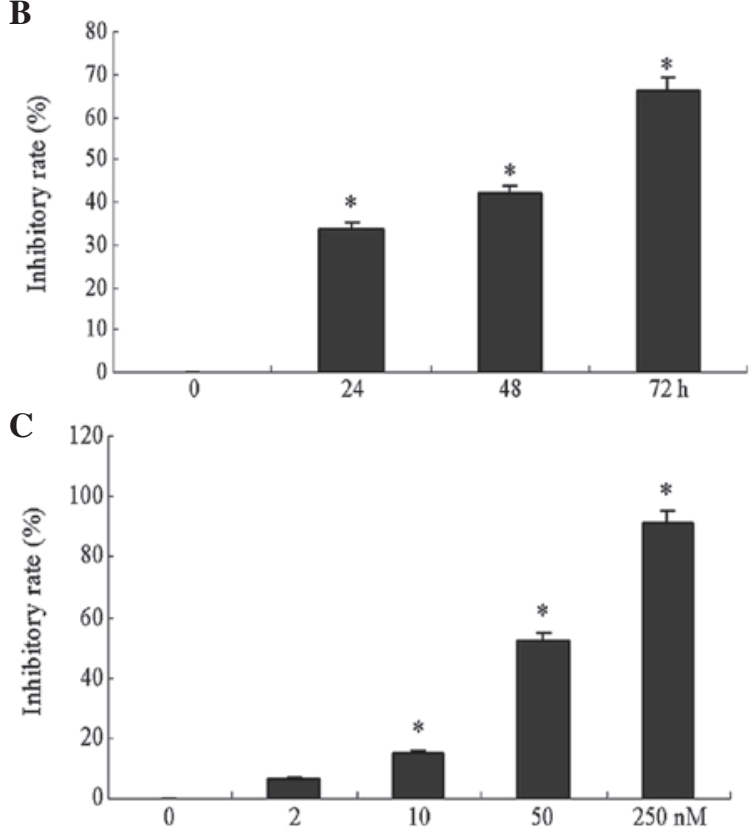

D
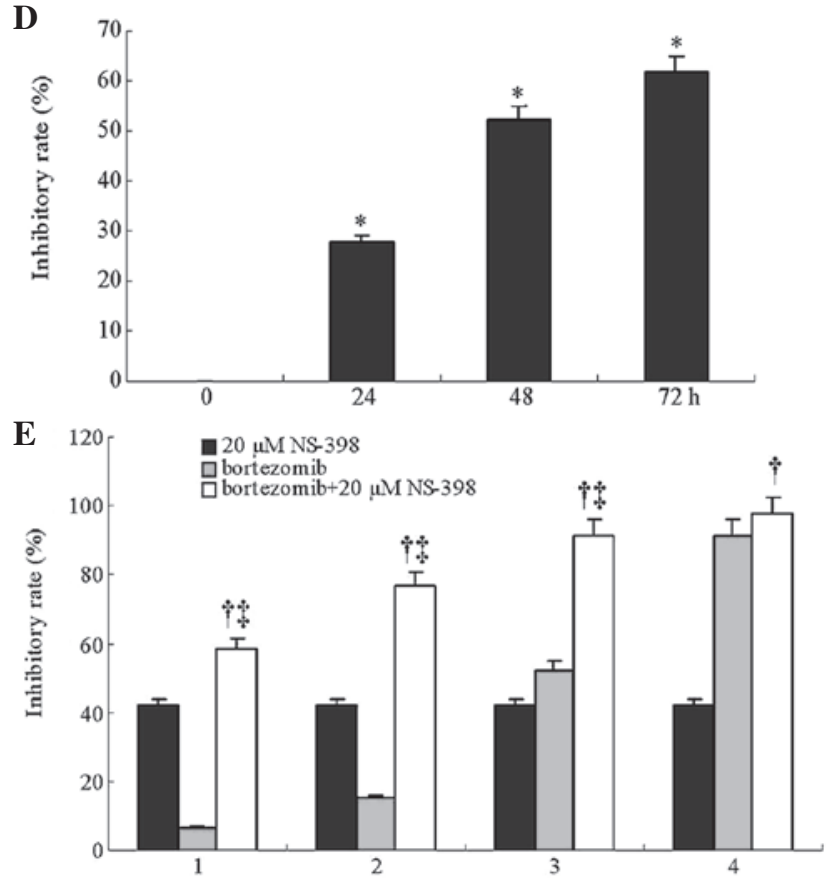

Figure 1. NS-398 and/or bortezomib induce cytotoxicity in RPMI8226 cells. Cells were treated with (A) various concentrations of NS-398 for $48 \mathrm{~h}$; (B) $20 \mathrm{nM} \mathrm{NS}-398$ for varying time periods; (C) various concentrations of bortezomib for $48 \mathrm{~h}$; (D) $10 \mathrm{nM}$ bortezomib for varying time periods; and (E) various concentrations of bortezomib for 48 h. 1, $2 \mathrm{nM} ; 2,10 \mathrm{nM}$; 3, $50 \mathrm{nM} ; 4,250 \mathrm{nM}$ bortezomib and $20 \mathrm{nM}$ NS-398. An MTT assay was performed as described in Materials and methods. The data are expressed as the mean $\pm \mathrm{SD}$. ${ }^{*} \mathrm{P}<0.05$ vs. control; ${ }^{\circ} \mathrm{P}<0.05$ vs. treatment with $20 \mathrm{nM}$ of NS-398; ${ }^{\dagger} \mathrm{P}<0.05$ vs. treatment with bortezomib.
Table I. NS-398 and/or bortezomib-induced cell cycle arrest in RPMI8226 cells.

\begin{tabular}{llll}
\hline Treated types & G0/G1 $(\%)$ & $\mathrm{S}(\%)$ & $\mathrm{G}_{2} / \mathrm{M}(\%)$ \\
\hline Control & $25.4 \pm 3.4$ & $51.3 \pm 3.5$ & $23.3 \pm 1.5$ \\
NS-398 & $41.6 \pm 3.3^{\mathrm{a}}$ & $38.6 \pm 2.7^{\mathrm{a}}$ & $19.8 \pm 1.4$ \\
Bortezomib & $47.5 \pm 3.8^{\mathrm{a}}$ & $29.9 \pm 2.2^{\mathrm{a}}$ & $22.6 \pm 1.3$ \\
Combination & $70.1 \pm 5.4^{\mathrm{b}}$ & $10.6 \pm 1.6^{\mathrm{b}}$ & $19.2 \pm 1.4$ \\
\hline
\end{tabular}

${ }^{\mathrm{a}} \mathrm{P}<0.05$ vs. control; ${ }^{\mathrm{b}} \mathrm{P}<0.05$ vs. either NS-398 or bortezomib alone. Cell cycle distribution of RPMI8226 cells following treatment with NS-398 $(20 \mu \mathrm{M})$, bortezomib (50 nM) and the two drugs combined (50 nM bortezomib and $20 \mu \mathrm{M}$ NS-398) for $48 \mathrm{~h}$. The data were expressed as the mean \pm SD of 3 independent experiments.

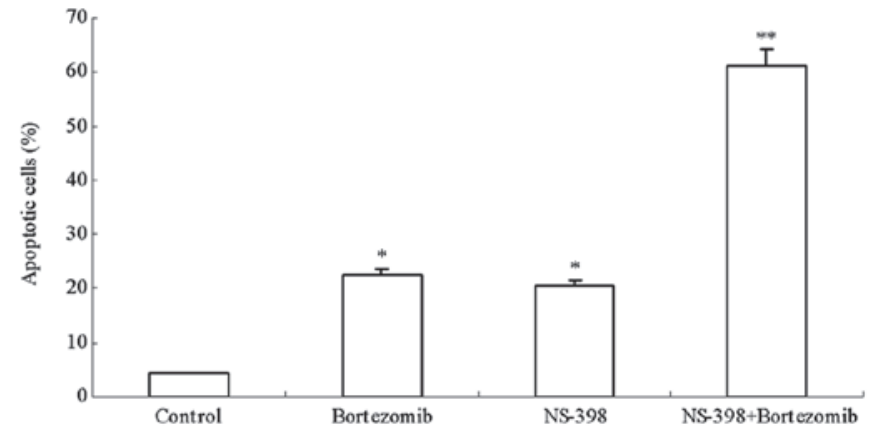

Figure 2. NS-398 and/or bortezomib induce apoptosis in RPMI8226 cells Cells were treated with NS-398 $(20 \mu \mathrm{M})$, bortezomib $(50 \mathrm{nM})$ or the two drugs combined ( $20 \mu \mathrm{M}$ NS-398 and $50 \mathrm{nM}$ bortezomib) for $48 \mathrm{~h}$. Subsequent to the indicated times, the RPMI8226 cells were fixed with ethanol and stained with PI, then sub-G1 was analyzed using flow cytometry. The sub-G1 was defined as apoptosis. Experiments were performed in duplicates and the data are expressed as the mean \pm SD. ${ }^{*} \mathrm{P}<0.05$ vs. control; ${ }^{* *} \mathrm{P}<0.05$ vs. either NS-398 or bortezomib alone. PI, propidium iodide.

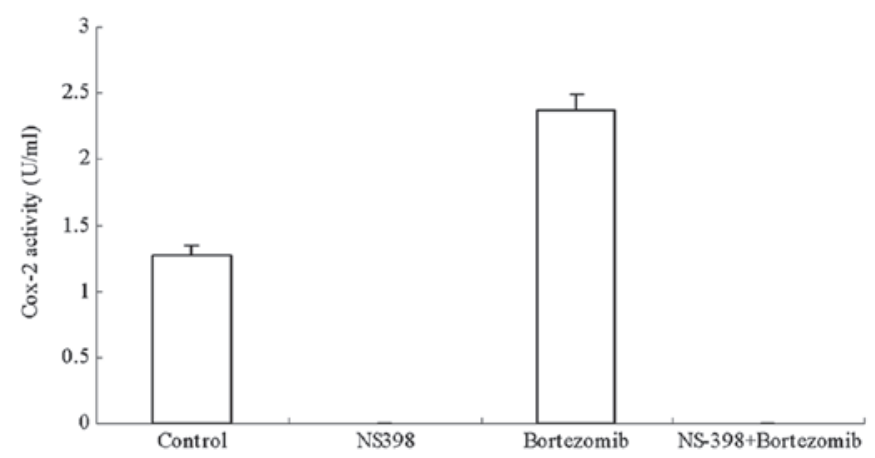

Figure 3. NS-398 and/or bortezomib inhibit Cox-2 activity in RPMI8226 cells. Cells were treated with NS-398 $(20 \mu \mathrm{M})$, bortezomib (50 nM) or NS-398 $(20 \mu \mathrm{M})+$ bortezomib $(50 \mathrm{nM})$ for $48 \mathrm{~h}$. Subsequent to the indicated time, the cells were collected and the Cox-2 activity was measured. Experiments were performed in duplicate and the data are expressed as the mean $\pm \mathrm{SD}$.

this was due to the downregulation of Cox-2 expression caused by NS-398 treatment, a western blot analysis was performed to investigate the protein level of Cox-2. It was observed that NS-398 had no obvious effect on the high Cox-2 protein 


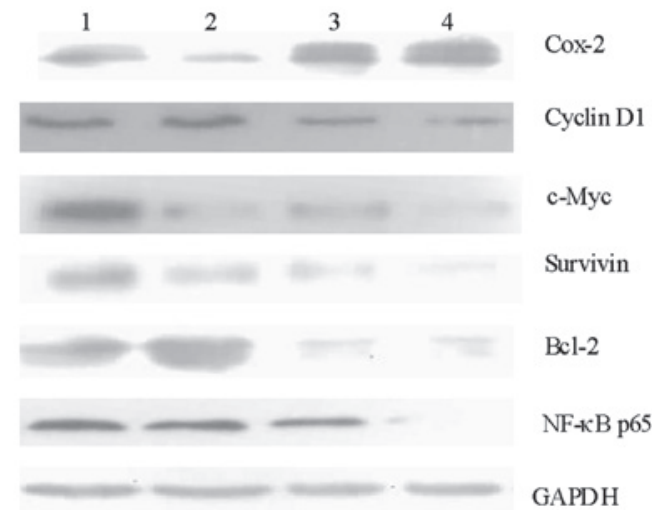

Figure 4. NS-398 and/or bortezomib inhibit NF-kB signaling in RPMI8226 cells. Cells were treated with NS-398, bortezomib or a combination of the two drugs for $48 \mathrm{~h}$. The protein levels of NF-kB, Bcl-2, c-Myc, Cox-2, cyclin D1 and survivin were then detected by western blot analysis. GAPDH served as a loading control. Lanes 1 , untreated cells (control); 2 , cells treated with NS-398 $(20 \mu \mathrm{M}) ; 3$, cells treated with bortezomib $(50 \mathrm{nM}) ; 4$, cells treated with NS-398 $(20 \mu \mathrm{M})$ and bortezomib $(50 \mathrm{nM})$.

level in the RPMI8226 cells treated with bortezomib (Fig. 4), suggesting that NS-398 inhibits the bortezomib-induced Cox-2 activity in RPMI8226 cells without modulating the expression of Cox-2.

NS-398 promotes bortezomib-induced downregulation of $N F-\kappa B$ signaling in RPMI8226 MM cells. It is well-known that bortezomib inhibits NF- $\kappa \mathrm{B}$ activity in MM cells. Therefore, we examined the activity of $\mathrm{NF}-\kappa \mathrm{B}$ and the expression of its downstream targets, including Bcl-2, c-Myc, cyclin D1 and survivin in RPMI8226 MM cells. Western blot analysis showed that the levels of NF- $\kappa \mathrm{B}$ p 65 , a marker of the activation of NF- $\kappa \mathrm{B}$ signaling, as well as those of Bcl-2, c-Myc, cyclin D1 and survivin, were significantly decreased upon combined treatment with NS-398 and bortezomib, compared with the untreated control or treatment with NS-398 or bortezomib alone. These results demonstrate that NS-398 and bortezomib act synergistically to inhibit NF- $\mathrm{B}$ signaling in RPMI8226 MM cells.

\section{Discussion}

Cox-2 is important in the regulation of growth and apoptosis in tumor cells $(13,14)$. Previous studies have indicated that Cox-2 is highly expressed in MM, and its overexpression has often been used as an indicator of poor prognosis (15). Cox-2 knockdown has been shown to induce the growth inhibition and apoptosis of RPMI8226 MM cells (16). NS-398 has been demonstrated to inhibit growth and induce the apoptosis of MM cells through Cox-2-dependent and -independent pathways (17). A previous study showed that the combination of bortezomib and aspirin, a classical Cox inhibitor, acted synergistically to inhibit proliferation and induce the apoptosis of human colorectal cells (10). However, to the best of our knowledge, no studies have been reported on the synergistic effects between NS398 and bortezomib in MM cells.

In the present study, NS-398 and bortezomib inhibited RPMI8226 cell growth in a time- and dose-dependent manner. When $20 \mu \mathrm{M}$ NS-398 was combined with various concentra- tions (2-250 nM) of bortezomib, the combined index ranged between 1.26 and 1.52 , with the exception of 1.03 , when a combination of $20 \mu \mathrm{M}$ of NS-398 and $250 \mathrm{nM}$ bortezomib was used, suggesting that this combination had synergetic growth inhibitory effects on the RPMI8226 cells.

To elucidate the mechanisms by which NS-398 enhanced the cytotoxicity of bortezomib in the MM RPMI8226 cells, we first examined apoptosis induction. Our data showed that the apoptotic rate of the combined group was significantly higher than that of either NS-398 or bortezomib treatment alone. This is in agreement with a previous study which indicated that NS-398 enhanced the growth inhibition of MM cells by dexamethasone or thalidomide treatment, and that the synergic effect was mainly mediated by the increase of apoptosis (18). In addition, we showed that NS-398 promotes bortezomib-induced cell cycle arrest of MM cells at the G0/G1 phase.

The sensitization of RPMI8226 cells to bortezomib was thought to be associated with the decreased activity of Cox-2. Our data indicated that NS-398 was able to completely inhibit Cox-2 activity, i.e., not only the endogenous activity in RPMI8226 cells, but also the enhanced activity induced by the bortezomib treatment. Notably, we found that NS-398 had no effects on Cox-2 expression, which was in agreement with a previous study (10). Thus, our results indicate that the NS-398-mediated inhibition of Cox-2 activity may increase the cytotoxicity of bortezomib in the MM cells.

Cox-2 inhibitors are known to act synergistically with chemotherapeutic agents in numerous cancer cells by downregulating the $\mathrm{NF}-\kappa \mathrm{B}$ target genes, such as Bcl-2, c-Myc and survivin (19-22). In the present study, we found that several downstream targeted genes of $\mathrm{NF}-\kappa \mathrm{B}$ signaling, including Bcl-2, c-Myc, cyclin D1 and survivin, were highly expressed in the RPMI8226 cells, indicating that the activation of $\mathrm{NF}-\kappa \mathrm{B}$ signaling contributes to the development of myeloma. Following the combined treatment with NS-398 and bortezomib, the expression of these $\mathrm{NF}-\kappa \mathrm{B}$ target genes was significantly decreased. These data indicate that the inhibition of the NF- $\kappa \mathrm{B}$ pathway is essential to the synergistic effect of NS-398 and bortezomib on the MM cells.

Bortezomib is used in MM patients based on the inhibition of $N F-\kappa B$ activity by the prevention of the proteasomal degradation of $\mathrm{I} \kappa \mathrm{B} \alpha$. However, a previous study indicated that bortezomib-induced cytotoxicity in MM cells is not associated with the inhibition of NF- $\kappa \mathrm{B}$ activity (23). This raised a question with regard to whether the $N F-\kappa B$ pathway remains a major therapeutic target of MM. Thus, we investigated the activity of NF- $\kappa \mathrm{B}$ in the RPMI8226 MM cells. Western blot analysis indicated that the level of NF- $\mathrm{B}$ p 65 in cells treated with a combination of bortezomib and NS-398 was significantly lower than in cells treated with bortezomib or NS-398 alone. Taken together, these results show that NF- $\kappa \mathrm{B}$ signaling is involved in the synergistic action between NS-398 and bortezomib against MM cells.

In summary, it was found that NS-398 and bortezomib acted synergistically to inhibit cell growth, arrest the cell cycle at the G1 phase and induce the apoptosis of MM cells. NS-398 enhanced the efficacy of bortezomib against MM cells in vitro and this was associated with the inhibition of $N F-\kappa B$ signaling. These findings suggest that the combined use of 
NS-398 and bortezomib may constitute a promising novel treatment protocol for MM patients.

\section{Acknowledgements}

This study was supported by the National Natural Science Foundation of China (grant no. 81172259).

\section{References}

1. Merchionne F, Perosa F and Dammacco F: New therapies in multiple myeloma. Clin Exp Med 7: 83-97, 2007.

2. Richardson PG, Barlogie B, Berenson J, et al: A phase 2 study of bortezomib in relapsed, refractory myeloma. N Engl J Med 348 2609-2617, 2003.

3. Hideshima T, Mitsiades C, Akiyama M, et al: Molecular mechanisms mediating antimyeloma activity of proteasome inhibitor PS-341. Blood 101: 1530-1534, 2003.

4. Nencioni A, Grünebach F, Patrone F, et al: Proteasome inhibitors: antitumor effects and beyond. Leukemia 21: 30-36, 2007.

5. Markovina S, Callander NS, O'Connor SL, et al: Bortezomibresistant nuclear factor-kappaB activity in multiple myeloma cells. Mol Cancer Res 6: 1356-1364, 2008.

6. Markovina S, Callander NS, O'Connor SL, et al: Bone marrow stromal cells from multiple myeloma patients uniquely induce bortezomib resistant NF-kappaB activity in myeloma cells. Mol Cancer 9: 176, 2010.

7. Levine L: Proteasome inhibitors: their effects on arachidonic acid release from cells in culture and arachidonic acid metabolism in rat liver cells. BMC Pharmacol 4: 15, 2004.

8. Rockwell P, Yuan H, Magnusson R and Figueiredo-Pereira ME: Proteasome inhibition in neuronal cells induces a proinflammatory response manifested by upregulation of cyclooxygenase- 2 , its accumulation as ubiquitin conjugates, and production of the prostaglandin PGE(2). Arch Biochem Biophys 374: 325-333, 2000.

9. Mbonye UR, Yuan C, Harris CE, et al: Two distinct pathways for cyclooxygenase-2 protein degradation. J Biol Chem 283 : 8611-8623, 2008.

10. Voutsadakis IA, Patrikidou A, Tsapakidis K, et al: Additive inhibition of colorectal cancer cell lines by aspirin and bortezomib. Int J Colorectal Dis 25: 795-804, 2010.

11. Liu JF, Zhu GJ, Jamieson GG, et al: NS-398 induces apoptosis in human esophageal cancer cells through inhibition of NF-kappaB downstream regulation of cyclooxygenase-2. Cancer Invest 27: 17-23, 2009.
12. Jin ZJ: Addition in drug combination. Zhongguo Yao Li Xue Bao 1: 70-76: 1980 (In Chinese).

13. Bae SH, Jung ES, Park YM, et al: Expression of cyclooxygenase-2 (COX-2) in hepatocellular carcinoma and growth inhibition of hepatoma cell lines by a COX-2 inhibitor, NS-398. Clin Cancer Res 7: 1410-1418, 2001.

14. Elder DJ, Halton DE, Crew TE and Paraskeva C: Apoptosis induction and cyclooxygenase-2 regulation in human colorectal adenoma and carcinoma cell lines by the cyclooxygenase-2-selective non-steroidal anti-inflammatory drug NS-398. Int J Cancer 86: 553-560, 2000.

15. Ladetto M, Vallet S, Trojan A, et al: Cyclooxygenase-2 (COX-2) is frequently expressed in multiple myeloma and is an independent predictor of poor outcome. Blood 105: 4784-4791, 2005.

16. Li QB, Chen ZC, You Y and Zou P: Small interfering RNA of cyclooxygenase-2 induces growth inhibition and apoptosis independently of Bcl-2 in human myeloma RPMI8226 cells. Acta Pharmacol Sin 28: 1031-1036, 2007.

17. Ding J, Tsuboi K, Hoshikawa H, et al: Cyclooxygenase isozymes are expressed in human myeloma cells but not involved in anti-proliferative effect of cyclooxygenase inhibitors. Mol Carcinog 45: 250-259, 2006.

18. Zhang M, Abe Y, Matsushima T, et al: Selective cyclooxygenase 2 inhibitor NS-398 induces apoptosis in myeloma cells via a Bcl-2 independent pathway. Leuk Lymphoma 46: 425-433, 2005.

19. Honjo S, Kase S, Osaki M, et al: COX-2 correlates with F-box protein, Skp2 expression and prognosis in human gastric carcinoma. Int J Oncol 26: 353-360, 2005.

20. Mizutani Y, Nakanishi H, Li YN, et al: Enhanced sensitivity of bladder cancer cells to cisplatin mediated cytotoxicity and apoptosis in vitro and in vivo by the selective cyclooxygenase- 2 inhibitor JTE-522. J Urol 172: 1474-1479, 2004.

21. Lin J, Hsiao PW, Chiu TH and Chao JI: Combination of cyclooxygenase- 2 inhibitors and oxaliplatin increases the growth inhibition and death in human colon cancer cells. Biochem Pharmacol 70: 658-667, 2005.

22. Kishimoto Y, Yashima K, Morisawa T, et al: Effects of cyclooxygenase-2 inhibitor NS-398 on APC and c-myc expression in rat colon carcinogenesis induced by azoxymethane. J Gastroenterol 37: 186-193, 2002.

23. Hideshima T, Ikeda $\mathrm{H}$, Chauhan $\mathrm{D}$, et al: Bortezomib induces canonical nuclear factor- $\mathrm{\kappa B}$ activation in multiple myeloma cells. Blood 114: 1046-1052, 2009. 